\title{
Differences in the Hemagglutinin Amino Acids of Japanese and US Influenza A/H3N2 Viral Isolates and their Relationship with Vaccine Strain Differences
}

\section{Yong Chong ${ }^{1^{*}}$ and Hideyuki Ikematsu ${ }^{2}$}

${ }^{1}$ Medicine and Biosystemic Science, Kyushu University Graduate School of Medical Sciences, 3-1-1 Maidashi, Higashi-Ku, Fukuoka 812-8582, Japan

2 Japan Physicians Association, 2-18-30 Hakataekihigashi, Hakata-ku, Fukuoka 812-0013, Japan

"Corresponding author: Yong Chong, Medicine and Biosystemic Science, Kyushu University Graduate School of Medical Sciences, 3-1-1 Maidashi, Higashi-Ku, Fukuoka 812-8582, Japan, Tel: 81-92-642-5228; Fax: 81-92-642-5247; E-mail: ychong@gj9.so-net.ne.jp

Received date: January 06, 2018; Accepted date: January 10, 2018; Published date: January 17, 2018

Copyright: $@ 2018$ Chong Y, et al. This is an open-access article distributed under the terms of the Creative Commons Attribution License, which permits unrestricted use, distribution, and reproduction in any medium, provided the original author and source are credited.

\begin{abstract}
The effects of vaccination on the dynamics of influenza virus remain largely unknown. Different $A / H 3 N 2$ vaccine strains were used in Japan and the United States (US) in the 2014-2015 season. To examine how different vaccine strains affect the selection of surviving variants, we compared hemagglutinin (HA) sequences in Japan with those in the US. A total of $85 \mathrm{~A} / \mathrm{H} 3 \mathrm{~N} 2$ samples from 38 vaccinated and 47 unvaccinated Japanese patients (33 from the 2013-2014 and 52 from the 2014-2015 Japanese seasons) were isolated and genetically analyzed using a nextgeneration sequencer for comparison with 113 US isolates (30 from the 2013-2014 season and 83 from the 2014-2015 season) referenced from the GenBank database. HA1 amino acid (AA) differences between Japan and the US for the 2014-2015 vaccine strains were found at sites 128 (epitope B), 142 (A), 145 (A) and 198 (B). 145S and $198 \mathrm{~S}$ in Japanese isolates, which matched with those of the 2014-2015 vaccine strain, significantly decreased between the two seasons, contrary to the full maintenance of US isolates $(57.6 \%$ vs. $5.8 \%$ for $145 \mathrm{~S}, \mathrm{P}<0.0001$; $100.0 \%$ vs. $75.0 \%$ for $198 \mathrm{~S}, \mathrm{P}=0.0012$ ). The predominance of $128 \mathrm{~A}$ and $142 \mathrm{G}$ was also lost in Japanese isolates, as observed while matching these AAs with those of the $2014-2015$ vaccine strain $(72.7 \%$ vs. $19.2 \%$ for $128 \mathrm{~A}$, $\mathrm{P}<0.0001 ; 75.8 \%$ vs. $15.4 \%$ for $142 \mathrm{G}, \mathrm{P}<0.0001$ ). Our data suggest that vaccine selection might be associated with the emergence of influenza variants genetically distant from vaccine strains.
\end{abstract}

Keywords: Influenza; Vaccination; Vaccine selection; Mutation; Hemagglutinin

\section{Introduction}

Annual outbreaks of influenza viruses result in a high morbidity and mortality in humans. A/H3N2 viruses are the most common and virulent of the influenza subtypes [1,2]. Antigenic drift, changes in antigenicity through the accumulation of mutations in the hemagglutinin (HA) gene, which encodes a major surface protein, is chiefly responsible for the continuing circulation of these viruses [1,2] As a result, influenza vaccines must be frequently updated based on new variant analyses. In recent seasons, however, the protection by influenza vaccines has been suboptimal [3-5].

It is possible that the immune pressure elicited by vaccination (vaccine pressure) has an effect on the selection of influenza variants that become epidemic in the following season; thus, understanding the mechanisms would contribute to more accurate HA prediction, which would be helpful for counteracting future epidemic viruses. Based on this hypothesis, we have been investigating the influence of vaccine pressure on the epidemic dynamics of influenza viruses.

In Japan, recent influenza vaccine strains have been selected according to the World Health Organization (WHO) recommendations; however, in the 2014-2015 Japanese season, an A/ $\mathrm{H} 3 \mathrm{~N} 2$ vaccine strain different from that recommended by the WHO was chosen in order to more efficiently avoid a decrease in antigenicity due to "egg-adaptation", as explained by the National Institute of
Infectious Diseases [6]. This circumstance presented us an opportunity to analyze how different vaccine strains affect the selection of surviving variants in different regions, based on the assumption that vaccine pressure has a certain effect on influenza epidemics.

The necessary data was gathered through our network of physicians throughout Japan who routinely collect influenza virus samples, along with patient information that includes vaccination history [7-10]. In this study, we determined the full-length sequence of HA genes of influenza $\mathrm{A} / \mathrm{H} 3 \mathrm{~N} 2$ viruses isolated from both vaccinated and unvaccinated patients in the 2013-2014 and 2014-2015 seasons, and compared amino acid (AA) mutations at different HAl AA sites between Japanese and the United States (US) vaccine strains, using these sequences for the Japanese isolates and the reference sequences for the US isolates.

\section{Materials and Methods}

\section{Sample collection}

Nasopharyngeal swabs for influenza virus isolation were collected and vaccination history was determined from patients who had a positive result on a rapid influenza antigen test, given at one of the member clinics of our nation-wide study network of general practitioners [7-10]. Informed consent was obtained from all patients. All patients were outpatients, and this study did not include any patients with severe chronic respiratory diseases, renal diseases, liver diseases, or heart failure. All viral samples were collected before the initiation of neuraminidase inhibitors (NAIs). Background 
Citation: Chong Y, Ikematsu H (2018) Differences in the Hemagglutinin Amino Acids of Japanese and US Influenza A/H3N2 Viral Isolates and their Relationship with Vaccine Strain Differences. J Vaccines Vaccin 9: 381. doi:10.4172/2157-7560.1000381

Page 2 of 6

information on these patients, including their vaccination history, was also collected. In this study, the isolates of 85 samples (33 from the 2013-14 season and 52 from the 2014-15 season) were genetically analyzed. In total, 38 isolates were obtained from vaccinated patients and 47 from unvaccinated patients. The seasonal influenza vaccine is available to all residents of Japan. All viral samples from vaccinated patients were collected more than four weeks after vaccination. A/ Texas/50/2012 (X-223) and A/NewYork/39/2012 (X-233A) were used in the Japanese influenza A/H3N2 vaccines for the 2013-14 and 2014-15 seasons, respectively. GenBank accession numbers of A/Texas/ 50/2012 and A/NewYork/39/2012 are KC892248 and KF790277, respectively. For the US data, 113 US isolates (30 from the 2013-2014 season and 83 from the 2014-2015 season) were referenced from the GenBank database. For the 2014-2015 season, all states of the US were searched for isolates and one to six were retrieved from all but thirteen states.

\section{Viral RNA extraction and RT-PCR}

Nasopharyngeal swabs from patients were soaked in virus transport medium and $75 \mu \mathrm{L}$ of the medium was cultured using Madin-Darby canine kidney (MDCK) cells. Viral RNA was extracted from infected MDCK cell culture supernatants using the Maxwell 16 LEV simply RNA Cells Kit (Promega, Madison, WI). The A/H3N2 subtype was determined by PCR [11]. RT-PCR was performed using the H3N2 RNA samples. PCR primers, synthesized based on the $3^{\prime}$ and $5{ }^{\prime}$ terminal nucleotides that are common to all human influenza A virus segments [12] were as follows: forward primer (Uni-12), 5'ACGCGTGATCAGCAAAAGCAGG-3' and reverse primer (Uni-13), 5'-ACGCGTGATCAGTAGAAACAAGG-3'. The PCR consisted of 31 cycles of a denaturing step at $94^{\circ} \mathrm{C}$ for $30 \mathrm{sec}$, an annealing step at $57^{\circ} \mathrm{C}$ for $30 \mathrm{sec}$, and an extension step at $72^{\circ} \mathrm{C}$ for $2 \mathrm{~min}$.

\section{Next generation sequencing}

A DNA library for Illumina sequencing was prepared using the Nextera XT DNA Sample Prep kit (Illumina, San Diego, CA).
Sequencing was conducted via a paired-end, $2 \times 250$ bp cycle run, using the Illumina MiSeq sequencing system and MiSeq Reagent Kit version 2 (300 Cycle) (Illumina) [13].

\section{Bioinformatic analysis}

Data processing was performed using the pipeline prepared by Amelieff Co [13]. The reference sequence was A/New York/396/2005 (H3N2) (GenBank accession numbers for the eight gene segments: CY002079, CY121123, CY121122, CY121117, CY121120, CY121119, CY121118, and CY121121). The HA amino acid (AA) sequence was deduced from the obtained nucleotide sequence.

\section{Nucleotide sequence accession number}

The sequence data from this study were deposited into the DDBJ/ EMBL/GenBank nucleotide sequence databases under the following accession numbers: LC111574-LC111606, and LC155845-LC155896.

\section{Statistical analysis}

Categorical variables between groups were tested using the Fisher's exact test. $\mathrm{P}<0.05$ was considered to be statistically significant. All statistical analyses were performed using the JMP Pro software, version 11 (SAS Institute, Inc., Cary, NC, USA).

\section{Results}

Table 1 shows the influenza $\mathrm{A} / \mathrm{H} 3 \mathrm{~N} 2$ vaccine strains selected in the US and Japan from the 2011-2012 to the 2015-2016 season. Different vaccine strains were used only in the 2014-2015 season during this five year period. In the US, A/Texas/50/2012 was chosen for the 2014-2015 season as well as in the previous season (2013-2014). In parallel, A/New York/39/2012 was selected for the 2014-2015 season in Japan (Table 1).

\begin{tabular}{|c|c|c|c|c|c|c|c|c|c|c|c|}
\hline \multicolumn{2}{|c|}{ AA (epitope) } & \multicolumn{3}{|c|}{ AA128 (epitope B) } & \multicolumn{2}{|c|}{$\begin{array}{l}\text { AA142 (epitope } \\
\text { A) }\end{array}$} & \multicolumn{2}{|c|}{$\begin{array}{l}\text { AA145 (epitope } \\
\text { A) }\end{array}$} & \multicolumn{3}{|c|}{ AA198 (epitope B) } \\
\hline Season (country) & Vaccine strain & $\mathbf{N}$ & A & $\mathrm{T}$ & $\mathbf{R}$ & G & $\mathbf{N}$ & $\mathbf{s}$ & $\mathbf{P}$ & $\mathbf{s}$ & A \\
\hline 2011-2012 (US and JPN) & A/Victoria/210/2009 & & & $\mathrm{T}$ & $R$ & & $\mathrm{~N}$ & & & & A \\
\hline 2012-2013 (US and JPN) & A/Victoria/361/2011 & & & $\mathrm{T}$ & $\mathrm{R}$ & & $\mathrm{N}$ & & & S & \\
\hline 2013-2014 (US and JPN) & A/Texas/50/2012 & $\mathrm{N}$ & & & $\mathrm{R}$ & & $\mathrm{N}$ & & $\mathrm{P}$ & & \\
\hline 2014-2015 (US) & A/Texas/50/2012 & $\mathrm{N}$ & & & $\mathrm{R}$ & & $\mathrm{N}$ & & $P$ & & \\
\hline 2014-2015 (JPN) & A/NewYork/39/2012 & & A & & & G & & S & & S & \\
\hline 2015-2016 (US and JPN) & A/Switzerland/9715293/2013 & & A & & & G & & s & & $\mathrm{s}$ & \\
\hline
\end{tabular}

Table1: Influenza A/H3N2 vaccine selection in Japan and the United States.

Of the AA sites known to be susceptible to mutation induced by egg-adaptation (sites 156, 186, and 219) [14], sites 186 and 219 have the possibility of different AAs between the Japanese and US vaccine strains of the 2014-2015 season, but these AA differences were not definite based on the result of reference sequencing. Identical AAs $(156 \mathrm{H}, 186 \mathrm{G}$, and $219 \mathrm{~S})$ were detected in all of the isolates from Japan and the US in both the 2013-2014 and 2014-2015 seasons. Based on these results, these three AA sites were excluded from our analysis. 
Citation: Chong Y, Ikematsu H (2018) Differences in the Hemagglutinin Amino Acids of Japanese and US Influenza A/H3N2 Viral Isolates and their Relationship with Vaccine Strain Differences. J Vaccines Vaccin 9: 381. doi:10.4172/2157-7560.1000381

Page 3 of 6

\begin{tabular}{|c|c|c|c|c|c|c|c|c|}
\hline \multicolumn{5}{|l|}{ AA145 } & \multicolumn{4}{|c|}{ AA198 } \\
\hline \multirow[b]{2}{*}{ Country } & \multirow[b]{2}{*}{ AA } & \multirow{2}{*}{$\begin{array}{l}2013-2014 \text { season } \\
\begin{array}{l}(145 \mathrm{~N} \text { in US and } \\
\left.\text { JPN })^{\mathrm{a}}\right)\end{array} \\
\begin{array}{l}\% \text { (No. of isolates/ } \\
\text { total isolates) }\end{array}\end{array}$} & \multirow{2}{*}{$\begin{array}{l}2014-2015 \text { season } \\
(145 \mathrm{~N} \text { in US and } \\
145 \mathrm{~S} \text { in JPN) } \\
\begin{array}{l}\% \text { (No. of isolates/ } \\
\text { total isolates) }\end{array}\end{array}$} & \multirow[b]{2}{*}{ P value ${ }^{b}$} & \multirow[b]{2}{*}{ AA } & \multirow{2}{*}{$\begin{array}{l}\begin{array}{l}2013-2014 \\
\text { (198P in US and JPN) }\end{array} \\
\begin{array}{l}\text { \% (No. of isolates/total } \\
\text { isolates) }\end{array}\end{array}$} & \multirow{2}{*}{$\begin{array}{l}2014-2015 \text { season } \\
(198 \mathrm{P} \text { in US and } \\
198 \mathrm{~S} \text { in JPN) } \\
\begin{array}{l}\text { \% (No. of isolates/ } \\
\text { total isolates) }\end{array}\end{array}$} & \multirow[b]{2}{*}{$P$ value } \\
\hline & & & & & & & & \\
\hline \multirow[t]{3}{*}{ US } & $\mathrm{s}$ & $100(30 / 30)$ & $98.8(82 / 83)$ & 1 & $s$ & $100(30 / 30)$ & $96.4(80 / 83)$ & 0.564 \\
\hline & $\mathrm{N}$ & $0(0 / 30)$ & $1.2(1 / 83)$ & 1 & $A$ & $0(0 / 30)$ & $0(0 / 83)$ & 1 \\
\hline & & & & & Other & $0(0 / 30)$ & $3.6(3 / 83)^{\mathrm{c}}$ & 0.564 \\
\hline \multirow[t]{2}{*}{ JPN } & $S$ & $57.6(19 / 33)$ & $5.8(3 / 52)$ & $<0.0001$ & $\mathrm{~s}$ & $100(33 / 33)$ & $75(39 / 52)$ & 0.0012 \\
\hline & $\mathrm{N}$ & $42.4(14 / 33)$ & $94.2(49 / 52)$ & $<0.0001$ & $A$ & $0(0 / 33)$ & $25(13 / 52)$ & 0.0012 \\
\hline \multirow[t]{2}{*}{ Vaccinated } & $\mathrm{s}$ & $43.8(7 / 16)$ & $4.5(1 / 22)$ & 0.0054 & $\mathrm{~s}$ & $100(16 / 16)$ & $63.6(14 / 22)$ & 0.0119 \\
\hline & $\mathrm{N}$ & $56.2(9 / 16)$ & $95.5(21 / 22)$ & 0.0054 & $A$ & $0(0 / 16)$ & $36.4(8 / 22)$ & 0.0119 \\
\hline \multirow[t]{2}{*}{ Unvaccinated } & S & $70.6(12 / 17)$ & $6.7(2 / 30)$ & $<0.0001$ & $S$ & $100(17 / 17)$ & $83.3(25 / 30)$ & 0.1435 \\
\hline & $\mathrm{N}$ & $29.4(5 / 17)$ & $93.3(28 / 30)$ & $<0.0001$ & $A$ & $0(0 / 17)$ & $16.7(5 / 30)$ & 0.1435 \\
\hline $\begin{array}{l}\text { aThis indicates } \\
\text { bThis indicates } \\
\text { 'This indicated } \\
\text { AA: Amino Acic }\end{array}$ & $\begin{array}{l}\text { is of } v \\
\text { OP in } \\
\text { 8S: Un }\end{array}$ & $\begin{array}{l}\text { ine strains in each seaso } \\
\text { of the frequency of iso } \\
\text { isolates and } 198 \mathrm{~L} \text { in one } \\
\text { States; JPN: Japan }\end{array}$ & $\begin{array}{l}\text { n. } \\
\text { ates displaying the indic } \\
\text { isolate. }\end{array}$ & ated AA be & $n$ the 20 & -2014 and 2014-2015 seas & sons. & \\
\hline
\end{tabular}

Table 2: Amino acid mutation at Hemagglutinin 1 (HA1) sites 145 and 198 of influenza A/H3N2 viruses isolated in Japan and the United States during the 2013-2014 and 2014-2015 seasons.

We examined definitely different HA1 AA sites between the two vaccine strains selected in the 2014-2015 season and found four AA sites (sites 128,142,145 and 198) (Table 1). The frequencies of AA mutations at sites 145 and 198 were compared for the isolates from Japan and the US (Table 2). In the vaccine strains of the 2013-2014 season, $145 \mathrm{~N}$ was present in both countries in the 2013-2014 season. In the 2014-2015 season, AA145 changed from $\mathrm{N}$ to $\mathrm{S}$ in the Japanese vaccine strain. $145 \mathrm{~S}$ was detected in all but one of the US isolates during the two seasons. In contrast, the predominance changed from $145 \mathrm{~S}$ to $145 \mathrm{~N}$ in Japan during this season $(57.6 \%$ for $145 \mathrm{~S}$ in the $2013-2014$ vs. $94.2 \%$ for $145 \mathrm{~N}$ in the 2014-2015, $\mathrm{P}<0.0001)$. In addition, the rate of $145 \mathrm{~S}$ in the 2014-2015 season was lower in the isolates from vaccinated than from unvaccinated patients $(4.5 \% \mathrm{vs}$. 6.7\%), although this difference was not statistically significant. AA198 changed from $\mathrm{P}$ to $\mathrm{S}$ in the Japanese vaccine strain for the 2014-2015 season, while the US vaccine strain remained unchanged (198P). $198 \mathrm{~S}$ was found in all of the US and Japanese isolates in the 2013-2014 season. In the 2014-2015 season, 198A emerged only in Japan $(0.0 \%$, $0 / 33$ isolates in the 2013-2014 vs. $25.0 \%, 13 / 52$ isolates in the 2014-2015, $\mathrm{P}=0.0012$ ). The rate of $198 \mathrm{~S}$ in the 2014-2015 season was lower in the isolates from vaccinated than from unvaccinated patients (63.6\% vs. 83.3\%).
The analysis of sites 128 and 142 is shown in Table 3 . In the 2013-2014 season, $128 \mathrm{~N}$ was present in the vaccine strains of both countries. In the 2014-2015 season, AA128 changed from N to A only in the Japanese vaccine strain. In the 2013-2014 season, the dominant AAs at site 128 were $128 \mathrm{~T}$ (63.3\%) in the US and 128A $(72.7 \%)$ in Japan. In the 2014-2015 season, the 128A found in the isolates from Japan decreased in frequency from $72.7 \%$ (24/33 isolates) to $19.2 \%$ $(10 / 52$ isolates $)(\mathrm{P}<0.0001)$. In addition, 128A dominance was lost in both the isolates from vaccinated and unvaccinated patients (from $93.8 \%$ to $22.7 \%$ in the vaccinated; from $52.9 \%$ to $16.7 \%$ in the unvaccinated); however, the rate of 128A in the 2014-2015 season was higher in the isolates from vaccinated than from unvaccinated patients (22.7\% vs. $16.7 \%)$. In the $2014-2015$ season, AA142 changed from R to $\mathrm{G}$ in the Japanese vaccine strain. AA combination at sites 128 and 142, 128A-142G, was found, as reported in our previous study [13]. Therefore, the predominance of $142 \mathrm{G}$, similar to that of $128 \mathrm{~A}$, was lost in the Japanese 2014-2015 season. In addition, the rate of $142 \mathrm{G}$ in the 2014-2015 season was lower in the isolates from vaccinated than from unvaccinated patients ( $13.6 \%$ vs. $16.7 \%)$, although this difference was not statistically significant.

\section{AA128}

AA142

\begin{tabular}{l|l}
$\begin{array}{l}2013-2014 \\
\text { season }\end{array}$ & $\begin{array}{l}\text { 2014-2015 season }(128 \mathrm{~N} \text { in US } \\
\text { and 128A in JPN) }\end{array}$
\end{tabular}

2013-2014

season $(142 R$

in US and JPN)
2014-2015 season (142R in US and $142 \mathrm{G}$ in JPN) 
Citation: Chong Y, Ikematsu H (2018) Differences in the Hemagglutinin Amino Acids of Japanese and US Influenza A/H3N2 Viral Isolates and their Relationship with Vaccine Strain Differences. J Vaccines Vaccin 9: 381. doi:10.4172/2157-7560.1000381

Page 4 of 6

\begin{tabular}{|c|c|c|c|c|c|c|c|c|}
\hline & & $\begin{array}{l}(128 \mathrm{~N} \text { in US } \\
\text { and JPNa) }\end{array}$ & & & & & & \\
\hline Country & AA & $\begin{array}{l}\% \quad \text { (No. of } \\
\text { isolates/total } \\
\text { isolates) }\end{array}$ & $\begin{array}{l}\% \quad \text { (No. of isolates/total } \\
\text { isolates) }\end{array}$ & $P$ valueb & AA & $\begin{array}{l}\% \quad \text { (No. of } \\
\text { isolates/total } \\
\text { isolates) }\end{array}$ & $\begin{array}{l}\% \quad \text { (No. of isolates/total } \\
\text { isolates) }\end{array}$ & $P$ value \\
\hline \multirow[t]{3}{*}{ US } & A & $36.7(11 / 30)$ & $4.8(4 / 83)$ & 0.0001 & G & $36.7(11 / 30)$ & $4.8(4 / 83)$ & 0.0001 \\
\hline & T & $63.3(19 / 30)$ & $95.2(79 / 83)$ & 0.0001 & $\mathrm{R}$ & $63.3(19 / 30)$ & $86.8(72 / 83)$ & 0.0132 \\
\hline & & & & & Other & $0.0(0 / 30)$ & $8.4(7 / 83) c$ & 0.1866 \\
\hline \multirow[t]{2}{*}{ JPN } & A & $72.7(24 / 33)$ & $19.2(10 / 52)$ & $<0.0001$ & G & $75.8(25 / 33)$ & $15.4(8 / 52)$ & $<0.0001$ \\
\hline & $T$ & $24.2(8 / 33)$ & $80.8(42 / 52)$ & $<0.0001$ & $R$ & $24.2(8 / 33)$ & $84.6(44 / 52)$ & $<0.0001$ \\
\hline \multirow[t]{2}{*}{ Vaccinated } & A & $93.8(15 / 16)$ & $22.7(15 / 22)$ & $<0.0001$ & G & $93.8(15 / 16)$ & $13.6(3 / 22)$ & $<0.0001$ \\
\hline & $\mathrm{T}$ & $6.2(1 / 16)$ & $77.3(17 / 22)$ & $<0.0001$ & $\mathrm{R}$ & $6.2(1 / 16)$ & $86.4(19 / 22)$ & $<0.0001$ \\
\hline \multirow[t]{2}{*}{ Unvaccinated } & A & $52.9(9 / 17)$ & $16.7(5 / 30)$ & 0.0182 & G & $58.8(10 / 17)$ & $16.7(5 / 30)$ & 0.0077 \\
\hline & $\mathrm{T}$ & $41.2(7 / 17)$ & $83.3(25 / 30)$ & 0.0182 & $\mathrm{R}$ & $41.2(7 / 17)$ & $83.3(25 / 30)$ & 0.0077 \\
\hline \multicolumn{9}{|c|}{ aThis indicates AAs of vaccine strains in each season. } \\
\hline \multicolumn{9}{|c|}{ bThis indicates a comparison of the frequency of isolates displaying the indicated AA between the $2013-2014$ and $2014-2015$ seasons. } \\
\hline \multicolumn{9}{|c|}{ cThis indicated $142 \mathrm{~K}$ in seven isolates. } \\
\hline \multicolumn{9}{|c|}{ AA: Amino Acid; US: United States; JPN: Japan } \\
\hline
\end{tabular}

Table 3: Amino acid mutation at Hemagglutinin 1 (HA1) sites 128 and 142 of influenza A/H3N2 viruses isolated in Japan and the United States during the 2013-2014 and 2014-2015 seasons.

As shown in Table 2, 198A was detected in 13 of 52 isolates (25.0\%) in the Japanese 2014-2015 season. Sites 198 and 128 were both within antigenic epitope B. 128A remained detectable in 10 of 52 isolates (19.2\%), as observed when including the isolates with 198A (Table 4).
On the other hand, $128 \mathrm{~A}$ was detected in only one isolate $(2.6 \%$, $\mathrm{P}=0.021$ ), when excluding the isolates with $198 \mathrm{~A}$ (Table 4). In addition, none of $128 \mathrm{~A}$ was detected in the vaccinated patients under the condition of 198A exclusion.

\begin{tabular}{|c|c|c|c|c|c|}
\hline \multicolumn{6}{|l|}{ AA128 } \\
\hline & \multirow{2}{*}{\multicolumn{2}{|c|}{$\begin{array}{l}\text { 2013-2014 season } \\
(128 \mathrm{~N} \text { in US and JPNa) }\end{array}$}} & \multicolumn{2}{|l|}{ 2013-2014 season (128A in JPN) } & \multirow[b]{3}{*}{$P$ value ${ }^{b}$} \\
\hline & & & \multirow{2}{*}{$\begin{array}{l}\text { Including 198A } \\
\% \text { (No. of isolates/total isolates) }\end{array}$} & \multirow{2}{*}{$\begin{array}{l}\text { Excluding 198A } \\
\text { \% (No. of isolates/total isolates) }\end{array}$} & \\
\hline Country & AA & $\begin{array}{l}\% \text { (No. of isolates/total } \\
\text { isolates) }\end{array}$ & & & \\
\hline \multirow[t]{2}{*}{ JPN } & A & $72.7(24 / 33)$ & $19.2(10 / 52)$ & $2.6(1 / 39)$ & 0.021 \\
\hline & $\mathrm{T}$ & $24.2(8 / 33)$ & $80.8(42 / 52)$ & $97.4(38 / 39)$ & 0.021 \\
\hline \multirow[t]{2}{*}{ Vaccinated } & A & $93.8(15 / 16)$ & $22.7(15 / 22)$ & $0.0(0 / 14)$ & 0.1336 \\
\hline & $\mathrm{T}$ & $6.2(1 / 16)$ & $77.3(17 / 22)$ & $100.0(14 / 14)$ & 0.1336 \\
\hline \multirow[t]{2}{*}{ Unvaccinated } & A & $52.9(9 / 17)$ & $16.7(5 / 30)$ & $4.0(1 / 25)$ & 0.2045 \\
\hline & $\mathrm{T}$ & $41.2(7 / 17)$ & $83.3(25 / 30)$ & $96.0(24 / 25)$ & 0.0077 \\
\hline
\end{tabular}


Table 4: Amino acid mutation at Hemagglutinin 1 (HA1) site 128 of influenza A/H3N2 isolates with or without 198A in the Japanese 2014-2015 season.

\section{Discussion}

Vaccine mismatch was of concern because of the antigenic change of vaccine strains due to egg-adaptation; however, the indicated adaptation sites, particularly sites 156,186 and 219 , exhibited identical AAs in all of the Japanese and US isolates. Thus, these egg-adaptation sites, included within known antigenic epitopes, did not seem to function as the main antigenic sites recognized by the host during the 2013-2014 and 2014-2015 seasons.

In the field of avian influenza, antigenic drift-related HA mutation due to escape from vaccine-induced immunity has been reported to cause vaccine failure $[15,16]$; however, the presence of vaccine-induced antigenic drift has not been demonstrated in humans. We recently reported evidence showing that vaccine pressure works to select influenza variants genetically distant from vaccine strains and affects the dynamics of the epidemic variants for humans [13]. At the beginning of the previous study, the phylogenetic method did not segregate viruses isolated from vaccinated and unvaccinated patients, as indicated in the report [17]. One possible explanation for the vaccine pressure not being reflected in the phylogenetic tree is that viruses that are able to infect vaccinated persons will become epidemic, irrespective of vaccination status. Viruses containing mutations that evade host immunity will be isolated from both the vaccinated and unvaccinated patients, resulting in no segregation in the phylogenetic tree of the viruses isolated from the vaccinated patients. We were first able to suggest the possible effect of vaccine pressure on HA mutation and its relation to the emergence of epidemic variants by directly comparing AA differences from the corresponding vaccine strains between isolates from vaccinated and unvaccinated patients. As shown in the phylogenetic tree in the previous study [13]. the epidemic viruses in the Japanese 2013-2014 and 2014-2015 seasons formed clades, which were segregated by AA mutations other than the four AA sites that were examined in this study. Thus, if we had based this study only on the results of phylogenetic tree analysis, we would have missed HA mutations possibly associated with the emergence of local variants.

Our present study allowed the examination of the influence of different vaccine strains on the HA mutations of influenza epidemic viruses, because different vaccine strains were selected between Japan and the US in the 2014-2015 season, in contrast to the 2013-2014 season. In the four different AA sites between Japanese and the US vaccine strains, the isolates from Japan showed more predominant AA mutations that were genetically distant from the corresponding vaccine strain, as compared to those from the US (Tables 2 and 3). Particularly, $145 \mathrm{~N}$, which was not detected in the US, was extremely predominant in Japan. 198A was observed in the isolates from Japan but was not detected in those from the US. HA AA site 145 is within antigenic epitope A and 198 within epitope B. Thus, genetic variation was generated in important antigenic sites, such as epitopes $\mathrm{A}$ and $\mathrm{B}$. This variation may be attributed to AA differences in the vaccine strains used in the two countries. As a result, these findings suggest the influence of vaccination on drift mutation.

AA sites 128 and 198 are both within antigenic epitope B [18]. In our analysis (Table 4$), 128 \mathrm{~A}$ was detected in $10(19.2 \%)$ of 52 Japanese isolates, when including the isolates with 198A. On the other hand, $128 \mathrm{~A}$ was detected in only one isolate (2.6\%, $1 / 39$ isolates), when excluding the isolates with 198A. Thus, 128A was detected in $9(69.2 \%)$ of 13 Japanese isolates with 198A. In contrast, almost all isolates without 198A exhibited 128T (97.4\%, 38/39 isolates). The acquisition of $198 \mathrm{~A}$ or $128 \mathrm{~T}$ appears to be alternative. These mutations within epitope B may have a similar effect as the structural change for antigenic drift.

The mechanisms responsible for HA mutation in influenza viruses seem to be very complicated, with many potentially contributing factors. Therefore, it was anticipated that not all HA mutations would be explained only by the immune pressure elicited by vaccination. The global epidemiological situation of $\mathrm{H} 3 \mathrm{~N} 2$ might also be associated with HA mutations, as indicated by global surveillance [19]. Thus, in the analysis of HA mutation in each region, the presence of local variants itself is not included as a prerequisite. In this study, we have obtained findings suggesting that there are local variants within epidemic $\mathrm{H} 3 \mathrm{~N} 2$ viruses in Japan. The emergence of $145 \mathrm{~N}$ and $198 \mathrm{~A}$ is especially intriguing (Table 2). The AA patterns of sites 128 and 142 appear to be similar in both the Japan and US samples, irrespective of AA differences at these sites between the samples of the two countries in the 2014-2015 seasonal vaccine (Table 3). Indeed, this result might be associated with the global spread of seasonal epidemic viruses. On the other hand, in Japan the emergence of 198A appears to be related to the mutation of site 128 (Table 4). Japan-specific selection of a vaccine strain in the 2014-2015 season might have accelerated the emergence of 198A and also affected the mutation pattern of site 128. Thus, our approach to the analysis of HA mutation revealed the presence of local variants that were not reflected by a phylogenetic analysis, and the emergence of these variants may be attributed, at least in part, to vaccine pressure.

The vaccine strain (A/Switzerland/9715293/2013) was chosen for the 2015-2016 season in both Japan and the US (Table 1). Interestingly, the A/NewYork/39/2012 strain used in the 2014-2015 season in Japan matched the four AA sites (128A, 142G, 145S, and 198S) with those of the 2015-2016 vaccine strain. As mentioned above, these four sites appeared to exhibit AA mutations that were genetically distant from the vaccine strain in the Japanese 2014-2015 season. These mutations, particularly $145 \mathrm{~N}$ and $198 \mathrm{~A}$, would be anticipated to emerge along with the match of the vaccine strain. Although our results are not conclusive, we are looking forward to investigating the HA AA sequences of the Japanese and US isolates in the 2015-2016 season, for confirmation.

A limitation of this study is that viral isolation could cause AA mutations during cultivation (MDCK passage). Direct sequencing from clinical samples would resolve this issue, although the direct use of respiratory samples involves the risk of detecting defective viruses with no growth activity potential.

It is unlikely that epidemic viruses in the 2014-2015 season were formed solely by AA mutations at the four sites that were different in the Japanese and US vaccine strains. It is unknown to what extent AA mutations at the four sites would be associated with the selection of 
epidemic variants in the two countries. Further study of the antigenic changes caused by AA mutations at these four sites will be necessary to determine the precise mechanisms of this challenging issue. However, the difference in the composition of epidemic viruses between Japan and the US is apparent. It would be natural to attribute this variation to AA differences in the vaccine strains, which might have induced different vaccine pressure.

\section{Acknowledgements}

We thank Kenjiro Shirane, Shinya Matsumoto, and Nozomi Noda for their technical support. We also thank Hiroyuki Sasaki and Donchon Kang for their support on this study.

We thank the following doctors for participating in this study: Shunsuke Akimitsu, Masaaki Chinen, Ken-ichi Doniwa, Keisuke Egashira, Yasuhiko Hirata, Miki Hirata, Nobuo Hirotsu, Tsuneo Inoue, Norio Iwaki, Kyosuke Kaji, Seizaburo Kashiwagi, Naoki Kawai, Takashi Kawashima, Kunio Kondo, Hiroko Kondo, Haruo Kuroki, Woon Joo Lee, Tetsunari Maeda, Koji Maehara, Tsuyoshi Makino, Shinro Matsuura, Akiko Miyata, Masashi Miyazaki, Kouichi Mochizuki, Kazuo Mori, Atsuko Nabeshima, Shin Nagao, Masatoshi Nakao, Kiyoshi Nishikawa, Yoshinori Nishimoto, Tadahiko Ogasawara, Jun Ogawa, Kaoru Oguchi, Yasuo Ontachi, Ietaka Sato, Yasuo Sato, Keigo Shibao, Kunihisa Shimomura, Shizuo Shindo, Kotoko Sumimoto, Yoshio Takasaki, Takeshi Tana, Osame Tanaka, Yuriko Tarukawa, Noriko Tateno, Keita Tatsushima, Satuki Tomita, Hiroaki Tomori, Hiroshi Ukai, Yutaka Wakasa, Masahiro Yaekashiwa, Norio Yamaguchi, Hareaki Yamamoto, Yasuhito Yamanishi, Yuji Yamashita, Satoshi Yamauchi, Takashi Yokoyama, Takato Yokoyama, Gen Yoshida, Hiroyuki Yoshimine, and Midori Yoshimura.

\section{Funding}

This work was supported by a grant-in-aid from the Ministry of Education, Culture, Sports, Science and Technology of Japan (26461505 to Y.C.)

\section{Authors' Contribution}

Yong Chong: Designed the study, carried out data analysis and drafted the manuscript.

Hideyuki Ikematsu: Designed the study, carried out data analysis and drafted the manuscript.

\section{Conflicts of Interest}

The authors indicate no potential conflicts of interest.

\section{References}

1. Carrat F, Flahault A (2007) Influenza vaccine: the challenge of antigenic drift. Vaccine 25: 6852-6862

2. Boni MF (2008) Vaccination and antigenic drift in influenza. Vaccine 26 3: C8-C14.

3. Belongia EA, Simpson MD, King JP, Sundaram ME, Kelley NS, et al. (2016) Variable influenza vaccine effectiveness by subtype: a systematic review and meta-analysis of test-negative design studies. Lancet Infect Dis 16: 942-951.

4. Flannery B, Clippard J, Zimmerman RK, Nowalk MP, Jackson ML, et al. (2015) Early estimates of seasonal influenza vaccine effectiveness - United States, January 2015. Morb Mortal Wkly Rep 64: 10-15.

5. Pebody RG, Warburton F, Ellis J, Andrews N, Thompson C, et al. (2015) Low effectiveness of seasonal influenza vaccine in preventing laboratoryconfirmed influenza in primary care in the United Kingdom: 2014/15 mid-season results. Euro Surveill 20: 21025.

6. http://www.nih.go.jp/niid/ja/iasr-sp/2301-related-articles/related-art icles-417/5130-dj4176.html.

7. Kawai N, Ikematsu H, Iwaki N, Satoh I, Kawashima T, et al. (2013) A prospective, Internet-based study of the effectiveness and safety of influenza vaccination in the 2001-2002 influenza season. Vaccine 21: 4507-4513.

8. Kawai N, Ikematsu H, Iwaki N, Satoh I, Kawashima T, et al. (2005) Factors influencing the effectiveness of oseltamivir and amantadine for the treatment of influenza: a multicenter study from Japan of the 2002-2003 influenza season. Clin Infect Dis 40: 1309-1316.

9. Kawai N, Ikematsu H, Iwaki N, Maeda T, Satoh I, et al. (2006) A comparison of the effectiveness of oseltamivir for the treatment of influenza A and influenza B: a Japanese multicenter study of the 2003-2004 and 2004-2005 influenza seasons. Clin Infect Dis 43: 439-444.

10. Kawai N, Ikematsu H, Hirotsu N, Maeda T, Kawashima T, et al. (2009) Clinical effectiveness of oseltamivir and zanamivir for treatment of influenza A virus subtype H1N1 with the H274Y mutation: a Japanese, multicenter study of the 2007-2008 and 2008-2009 influenza seasons. Clin Infect Dis 49: 1828-1835.

11. Stockton J, Ellis JS, Saville M, Clewley JP, Zambon MC (1998) Multiplex PCR for typing and subtyping influenza and respiratory syncytial viruses. J Clin Microbiol 36: 2990-2995.

12. Zhou B, Donnelly ME, Scholes DT, St George K, Hatta M, et al. (2009) Single-reaction genomic amplification accelerates sequencing and vaccine production for classical and Swine origin human influenza viruses. J Virol 83: 10309-10313.

13. Chong Y, Ikematsu H (2017) Effect of seasonal vaccination on the selection of influenza A/H3N2 epidemic variants. Vaccine 35: 255-263.

14. Skowronski DM, Janjua NZ, De Serres G, Sabaiduc S, Eshaghi A, et al. (2014) Low 2012-13 influenza vaccine effectiveness associated with mutation in the egg-adapted $\mathrm{H} 3 \mathrm{~N} 2$ vaccine strain not antigenic drift in circulating viruses. PLoS ONE 9: e92153.

15. Swayne DE, Suarez DL, Spackman E, Jadhao S, Dauphin G, et al. (2015) Antibody Titer Has Positive Predictive Value for Vaccine Protection against Challenge with Natural Antigenic-Drift Variants of H5N1 HighPathogenicity Avian Influenza Viruses from Indonesia. J Virol 89: 3746-3762.

16. Connie Leung YH, Luk G, Sia SF, Wu YO, Ho CK, et al. (2013) Experimental challenge of chicken vaccinated with commercially available $\mathrm{H} 5$ vaccines reveals loss of protection to some highly pathogenic avian influenza H5N1 strains circulating in Hong Kong/China. Vaccine 31: 3536-35342.

17. Dinis JM, Florek NW, Fatola OO, Moncla LH, Mutschler JP, et al. (2016) Deep Sequencing Reveals Potential Antigenic Variants at Low Frequencies in Influenza A Virus-Infected Humans. J Virol 90: 3355-3365.

18. Wiley DC, Wilson IA, Skehel JJ (1981) Structural identification of the antibody-binding sites of Hong Kong influenza haemagglutinin and their involvement in antigenic variation. Nature 289: 373-378.

19. Bedford T, Riley S, Barr IG, Broor S, Chadha M, et al. (2015) Global circulation patterns of seasonal influenza viruses vary with antigenic drift. Nature 523: 217-220. 